\title{
COMPREENSÃO ESCRITA EM LÍNGUA INGLESA: USO DE ESTRATÉGIAS DA PEDAGOGIA DE GÊNEROS
}

\author{
Ana Paula Carvalho Schmidt ${ }^{1}$ \\ Sara Regina Scotta Cabral ${ }^{2}$
}

Resumo: O ensino de língua inglesa no contexto da educação básica brasileira envolve diversos aspectos da aprendizagem de línguas adicionais; dentre eles, destacamos 0 aspecto educativo. Com isso, a formação de cidadãos abertos ao diálogo intercultural (BRASIL, 2006, p. 96) é encorajada, de forma que os estudantes tenham acesso aos bens culturais produzidos e veiculados na língua alvo. Para isso, são necessárias abordagens que levem em consideração a ampla gama de aspectos socioculturais subjacentes à aprendizagem de línguas adicionais. Nesse sentido, com base no quadro teórico da Linguística SistêmicoFuncional (HALLIDAY; MATTHIESSEN, 2014), especificamente, do Programa Ler para Aprender (ROSE; MARTIN, 2012), analisamos as questões de língua inglesa do Exame Nacional de Ensino Médio (ENEM) do ano de 2017, Caderno 1 - Azul. A partir dessa análise, propomos procedimentos pedagógicos de compreensão escrita. Esses resultados são parciais e fazem parte de um projeto de doutorado que está em fase inicial.

Palavras-chave: Compreensão escrita. Pedagogia de Gêneros. Ensino de língua inglesa.

\section{READING COMPREHENSION IN ENGLISH: USING GENRE PEDAGOGY STRATEGIES}

Abstract: The teaching of English in Brazilian basic education involves various aspects of learning additional languages, of which we highlight the educational one. It means that the education of citizens who are open to intercultural dialogue (BRASIL, 2006, p. 96) shall be encouraged so that students have access to the cultural goods produced and consumed in the target language. In order to do that, approaches that take into consideration the wide range of sociocultural aspects underlying the learning of additional languages are needed. In this sense, based on the theoretical framework developed in the Systemic Functional Linguistics (HALLIDAY; MATTHIESSEN, 2014), specifically in the Reading to Learn Program (ROSE; MARTIN, 2012), we analyze a set of questions from the 2017 edition of the Exame Nacional do Ensino Médio (ENEM), a Brazilian assessment exam. From

\footnotetext{
1 Doutoranda em Letras/Estudos Linguísticos na Universidade Federal de Santa Maria, Santa Maria, RS, Brasil. O presente trabalho foi realizado com apoio do CNPq, Conselho Nacional de Desenvolvimento Científico e Tecnológico - Brasil. E-mail: ana-gcarvalho@hotmail.com.

2 Docente do Departamento de Letras Vernáculas da Universidade Federal de Santa Maria (UFSM). Doutora em Estudos Linguísticos pelo Programa de Pós -Graduação em Letras da Universidade Federal de Santa Maria. Email: sara.scotta.cabtal@gmail.com.
} 
this analysis, we propose reading comprehension pedagogic procedures. These results are partial since they are part of a doctoral thesis project, which is in its initial stage.

Keywords: Reading comprehension. Genre Pedagogy. English language teaching.

\section{INTRODUÇÃO}

O discurso sobre a importância da língua inglesa para a globalização, a ciência, a tecnologia, os negócios e a mídia, tem sido recorrente no debate acerca do papel que essa língua passou a desempenhar na sociedade (ÁLVARES, 2016; CRYSTAL, 2003; SANTOS, 2011; ZACCHI, 2006),

principalmente após a Segunda Guerra Mundial. No Brasil, esse discurso tornou-se predominante em termos geopolíticos, devido às "aspirações

alimentadas por muito tempo de ser um grande ator regional, [...] confrontadas com o duplo desafio de reivindicar seu papel no continente e também projetar sua imagem para o resto do mundo" (RAJAGOPALAN, 2008, p. 186, tradução nossa).

Tal discurso tem encontrado eco no contexto educacional como justificativa para o ensino de língua inglesa, tanto na perspectiva dos estudantes (SANTOS, 2011; SCHMIDT; FIGHERA, 2016) quanto dos professores (MACIEL, 2013; ZACCHI, 2006). Entretanto, justificar a importância do ensino de língua inglesa no contexto brasileiro essencialmente por meio de objetivos utilitaristas, desconsidera o aspecto educativo da aprendizagem de uma língua adicional. Com isso, negligencia- se a formação de cidadãos abertos ao diálogo intercultural (BRASIL, 2006, p. 96), aos quais seja proporcionado acesso aos bens culturais produzidos e veiculados na língua alvo. Portanto, são necessárias abordagens que levem em consideração a ampla gama de aspectos socioculturais subjacentes à aprendizagem de língua inglesa.

Com base nessas premissas, este trabalho tem como objetivo analisar questões da edição de 2017 da prova de língua inglesa do Exame Nacional de Ensino Médio (ENEM) para propor procedimentos pedagógicos de compreensão escrita para estudantes do ensino médio. O embasamento teórico está fundamentado nos estudos desenvolvidos na Linguística Sistêmico- Funcional 
(HALLIDAY; MATTHIESSEN, 2014). Nessa perspectiva, a linguagemé vista como "um recurso para construir significado" (HALLIDAY; MATTHIESSEN, 2014, p. 3), por meio das escolhas léxico-gramaticais feitas pelo falante/escritor. Esse quadro teórico tem embasado diversos trabalhos que investigam a aplicação dessa teoria linguística em contextos específicos, sendo um deles o educacional (JOHNS, 2002; JONES; LOCK, 2011; LOCK, 1996; SCHLEPPEGRELL, 2004).

Dentre esses trabalhos, colocamos em destaque o programa Ler para Aprender, criado na década de 1990, na Austrália, com foco no ensino de leitura e escrita para estudantes do ensino fundamental e médio, em ambientes desfavorecidos. Esse programa sugere estratégias que subsidiem a aprendizagem do conteúdo das disciplinas do currículo, pormeio de textos escritos em língua inglesa (ROSE, 2015, p. 1).

Ao longo dos anos, três ciclos de aprendizagem foram desenvolvidos nesse programa, inicialmente conhecidos como: a) modelagem; b) negociação conjunta e c) construção independente (ROSE; MARTIN, 2012; ROSE, 2015). Em desenvolvimentos posteriores da teoria, a prática em sala de aula passou a ser organizada da seguinte forma: 1) apresentação do conteúdo pelo professor (preparação para a leitura), 2) (leitura detalhada), 3) atividade guiada com toda turma (reescrita conjunta), 4) atividade guiada individualmente (reescrita individual).

A primeira etapa envolve a desconstrução do texto por meio da identificação do gênero de que é um exemplar e das etapas de organização esquemática, de elementos não verbais e, em adição, da realização de previsões acerca do assunto do texto. Na segunda etapa, há a explicitação do significado de linguagem abstrata e/ou técnica por meio de elaboração conjunta entre professor e estudantes. $\mathrm{Na}$ terceira etapa, o campo para um novo texto, pertencente ao mesmo gênero, é construído, e a escrita é produzida de forma colaborativa com auxílio e necessárias adaptações feitas pelo professor (ROSE; MARTIN, 2012, p. 64). Por fim, a quarta etapa "consiste de estratégias intensivas que são utilizadas para ensinar habilidades fundamentais em leitura e escrita no contexto de textos do currículo escolar" (ROSE; MARTIN, 2012, p. 148, tradução nossa). 
Como recorte para o presente trabalho, a primeira etapa, de preparação para a leitura, será o foco para a elaboração dos procedimentos pedagógicos. $\mathrm{Na}$ próxima seção, indicamos o universo de análise da pesquisa e a constituição do corpus, bem como detalhamos as ações da etapa de preparação para a leitura que subsidiam a compreensãoescrita.

\section{METODOLOGIA}

Este estudo, de base qualitativa, tem por universo de análise a prova de Linguagens, Códigos e suas Tecnologias e Redação/Prova de Ciências Humanas e suas Tecnologias, Caderno 1 - Azul, da edição de 2017 do ENEM. O corpus é constituído por cinco textos da seção de língua inglesa. Com base na taxonomia de famílias de gêneros mapeados no contexto escolar australiano (MARTIN; ROSE, 2008), local onde foi desenvolvida a abordagem da Pedagogia de Gêneros, buscamos, em primeiro lugar, identificar a qual gênero pertencem os textos que acompanham as questões da seção em foco. A seguir, selecionamos um desses textos para exemplificar procedimentos de preparação para a leitura.

\section{RESULTADOS}

Os passos de preparação para a leitura consistem em esmiuçar elementos que possam contribuir para uma primeira aproximação a um texto produzido em uma língua com a qual os estudantes possuam pouca familiaridade. O Quadro 1 apresenta uma classificação detalhada dos gêneros textuais/discursivos materializados nos textos que acompanham as questões da prova de língua inglesa do ENEM de 2017. Conforme pode ser observado, quatro dos cinco gêneros cumprem a função social de engendraruma avaliação. Destes, o primeiro é uma resenha sobre o filme Frida, o terceiro é um anúncio publicitário sobre troca de óleo, o quarto é uma carta de uma leitora do jornal norte-americano New York Times, em resposta à uma reportagem veiculada anteriormente, sobre o assassinato de uma menina de dois anos por seu irmão de ci nco; finalmente, o quinto é um guia turístico sobre Israel.

Quadro 1 - Gêneros textuais/discursivos na seção de língua inglesa do 


\section{ENEM/2017}

\begin{tabular}{|c|c|c|c|c|}
\hline Questão & Família & $\begin{array}{c}\text { Função } \\
\text { social }\end{array}$ & Gênero & $\begin{array}{c}\text { Propósito } \\
\text { específico }\end{array}$ \\
\hline 01 & Reação a textos & avaliar & Resenha (de f ilme) & $\begin{array}{c}\text { avaliar um } \\
\text { objeto cultural }\end{array}$ \\
\hline 02 & Estórias & envolver & Notícia & $\begin{array}{l}\text { relatar eventos } \\
\text { significativos }\end{array}$ \\
\hline 03 & Argumentos & avaliar & $\begin{array}{c}\text { Exposição } \\
\text { (anúncio publicitário) }\end{array}$ & $\begin{array}{l}\text { argumentar um } \\
\text { ponto de vista }\end{array}$ \\
\hline 04 & Reação a textos & avaliar & $\begin{array}{c}\text { Resposta crítica } \\
\text { (carta do leitor) }\end{array}$ & $\begin{array}{c}\text { reagir à } \\
\text { mensagem } \\
\text { de um } \\
\text { texto }\end{array}$ \\
\hline 05 & Argumentos & avaliar & $\begin{array}{c}\text { Exposição } \\
\text { (guia turístico) }\end{array}$ & $\begin{array}{c}\text { argumentar } \\
\text { um ponto de } \\
\text { vista }\end{array}$ \\
\hline
\end{tabular}

Fonte: Autora, com base em Gerhardt, 2017, p. 168.

Essa classificação detalhada dos gêneros textuais/discursivos contribui para orientar professores de língua inglesa na preparação de atividades que visem tornar explícitos tanto o propósito social quanto a estrutura esquemática dos textos. Para a construção de um exemplo de preparação para a leitura, descartamos o gênero exposição - anúncio publicitário, por apresentar, predominantemente, elementos não verbais. Nesse caso, seria necessário recorrer ao aporte teórico dos estudos sobre multimodalidade para explanar como se dá a construção de sentido por outros meios além da modalidade verbal escrita. Dos três textos restantes, selecionamos a resenha, pois chama-nos a atenção a ausência de título e das etapas iniciais que caracterizariam esse texto como uma resenha (ver Quadro 2), conforme classificação sugerida por Rothery e Stenglin (2000).

Quadro 2 - Organização esquemática do gênero resenha

\begin{tabular}{|c|c|}
\hline omitido & Contextualização \\
\hline omitido & Descrição \\
\hline
\end{tabular}


One of the things that made an incredible impression on me in the film was Frida's comfort in and celebration of her own unique beauty. She didn't try to $f$ it into conventional ideas or images about womanhood or what makes someone or something beautiful.

Instead, she fully inhabited her own unique gifts, articularly caring what other people thought. She magnetic and beautiful in her own right. She ed for years, not to be a commercial success or e discovered, but to express her own inner pain, family, love and culture. She absolutely and utely was who she was. The trueness of her own ue vision

Fonte: Autora, com base no texto disponível na íntegra em: <p://www.etbscreenwriting.com/fridaday-thirty-five-40movies40days/>. Acesso em 21 mai. 2018.

A identificação desse excerto como parte de um texto que promove uma avaliação foi possível por meio do mapeamento de mecanismos linguísticos de posicionamento no texto. A autora da resenha utiliza marcadores léxicogramaticais, por exemplo adjetivos (incredible, unique, magnetic), para construir uma avaliação positiva do filme.

A ênfase dada à etapa denominada Avaliação, ao selecioná-la para constituir uma questão do exame, corrobora o panorama recorrente na maior parte das questões de língua inglesa do caderno analisado: parece haver uma demanda para que os estudantes concluintes do ensino médio possuam conhecimento linguístico que torne possível identificar e interpretar um texto avaliativo em língua adicional. Entretanto, como o texto apresentado na prova constitui-se em um excerto de uma resenha e o leitor toma conhecimento desse texto por meio do enunciado da questão, que emprega a denominação "comentário" (Quadro 3), o processo de compreensão textual pode ser prejudicado.

Quadro 3 - Questão 01 de língua inglesa

Questão 01

A autora desse comentário sobre o filme Frida mostra-se impressionada com o fato de a pintora: 
a) ter uma aparência exótica

b) vender bem a sua imagem

c) ter grande poder desedução

d) assumir sua beleza singular

e) recriar-se por meio da pintura

Fonte: http://portal.inep.gov.br/web/guest/provas-e-gabaritos

Tal procedimento pode trazer dúvidas ao aluno, uma vez que o texto poderia ser identificado, em uma leitura preliminar, como uma descrição da pintora mexicana Frida Khalo. A palavra "comentário", por constituir um nome genérico, não faz alusão ao gênero que está sendo trabalhado na questão, a resenha de um filme. Trata-se de uma adaptação para a proposta do exame, sem qualquer referência ao gênerotextual/discursivo.

Como o propósito deste trabalho é partir do mapeamento dos textos que integram o exame e sugerir a exploração de um texto avaliativo, em uma etapa de preparação para a leitura, a seguir apresentamos um número de procedimentos/atividades sequenciais que julgamos importantes, para que os alunos possam ter melhor desempenho no processo de leitura e compreensão de textos dessa natureza:

1) Distribuição de cópias do texto completo (resenha do filme Frida) aos estudantes;

2) Identificação da estrutura composicional e das respectivas marcas linguísticas;

3) Nomeação do gênero textual/discursivo e posterior discussão com os estudantes sobre seu conhecimento prévio e participação nesse gênero;

4) Explicação, por escrito em língua inglesa, das etapas do gênero;

5) Revisão do campo ${ }^{3}$ : discussão sobre o possível conteúdo/assunto do texto;

6) Releitura do texto, desta vez com novos comentários, estes de cunho mais avaliativo sobre a qualidadedo texto.

Após a distribuição do texto aos alunos, o professor deverá comentar sobre a(s) etapa(s) que constituem o gênero, a fim de que os estudantes possam identifica-las e fazerem associações com palavras - as marcas linguísticas - que 
caracterizam cada uma dessas etapas. Comentários sobre a funcionalidade de cada etapa e também das marcas linguísticas deverão ser feitos, a fim de orientar os alunos ao propósito comunicativo principal do gênero. No passo 3, o professor nomeia o gênero para fornecer suporte àqueles estudantes que, porventura, não tenham tido acesso a esse gênero, mesmo em língua materna, em vez de solicitar que os estudantes o denominem, supondo um possível conhecimento prévio.

A partir do resultado das interações no passo 2, caso a maioria dos estudantes tenham tido contato prévio com o gênero, no passo 3, os estudantes poderiam fazer previsões, oralmente, ou caso tenhamassistido ao filme, completar a informação que falta, em conjunto, enquanto o professor anota as previsões no quadro, em língua inglesa, uma vez que as demais etapas do gênero foram omitidas na prova. Além disso, esse passo favorece as trocas pedagógicas iniciais para reconhecimento do contexto de produção de um texto (quem escreve, quem lê, etc.). O passo 3, de identificação e explicação das etapas do gênero visa tornar explícito para os estudantes que os gêneros se organizam em uma estrutura relativamente estável e cumprem propósitos específicos, como entreter, persuadir, informar.

Na etapa 4, da leitura em voz alta, o professor pode guiar os estudantes a fazer marcações no texto, chamando a atenção para datas, nomes próprios e palavras cognatas.Com exceção da leitura do texto, todos os demais passos podem ser conduzidos em língua portuguesa a fim de estabelecer uma relação de confiança com os estudantes, de modo que eles sintam-se estimulados a participar das interações.

\section{CONSIDERAÇÕES FINAIS}

Neste trabalho, apresentamos um exemplo de como provas anteriores do ENEM, da área de Linguagens, Códigos e suas Tecnologias - língua inglesa, podem servir de ponto de partida para a elaboração de atividades didáticas que visem familiarizar estudantes de ensino médio com os gêneros textuais/discursivos que fazem parte desse exame. O exemplo de atividade apresentado teve por embasamento teórico a Linguística Sistêmico-Funcional e a Pedagogia de 


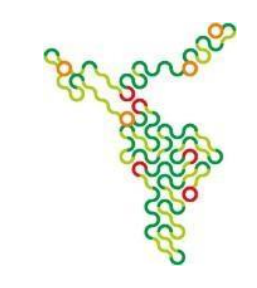

Gêneros.

Embora a amostra seja pequena (5 textos) e, portanto, não nos possibilite fazer generalizações para o ensino de inglês como língua adicional, algumas tendências podem ser observadas. Por exemplo, a predominância de gêneros cuja função social é avaliar. Além disso, destacamos a importância da Linguística Sistêmico-Funcional como uma ferramenta para a análise de materiais didáticos e adaptação/elaboração de atividades de compreensão escrita. Para desenvolvimentos futuros da pesquisa, a análise será ampliada para incluir as questões das provas de Linguagens, Códigos e suas Tecnologias dos últimos cinco anos e serão desenvolvidas atividades que contemplem as demais fases do ciclo de ensino e aprendizagem da Pedagogia de Gêneros.

\section{Referências}

ÁLVARES, S. A ciência fala inglês? em tempos de mudança. Nascer e crescer: Revista de Pediatria do Centro Hospitalar do Porto, vol. XXV, n.․ 3, 2016. Disponível em:

$<$ http://www.scielo.mec.pt/pdf/nas/v25n3/v25n3a01.pdf>. Acesso em 19 mai. 2018.

BRASIL. Ministério da Educação e Instituto Nacional de Estudos e Pesquisas Educacionais Anísio Teixeira (INEP). Exame Nacional do Ensino Médio. Caderno Azul. Brasília,2017.

- Ministério da Educação. Orientações curriculares para o ensino médio: linguagens, códigos e suas tecnologias. Brasília: Ministério da Educação/Secretaria de Educação Básica, 2006.

CRYSTAL, D. English as a global language. Cambridge: Cambridge University Press, 2003.

GERHARDT, C. C. Investigações dos gêneros episódio e exemplum na perspectiva Sistêmico- Funcional em livros didáticos de língua portuguesa do ensino fundamental. 2017. $234 \mathrm{f}$.

Dissertação (Mestrado em Letras/Estudos Linguísticos) - Universidade Federal de Santa Maria. Santa Maria. 2017.

HALLIDAY, M. A. K.; MATTHIESSEN, C. M. I. M. An introduction to Functional Grammar. 4th. ed. London: Edward Arnold, 2014.

JOHNS, A.M (org.). Genre in the classroom: Multiple Perspectives. Mahwah, N.J: Lawrence Erlbaum, 2002. 
JONES, R. H.; LOCK, G. Functional Grammar in the ESL classroom: noticing, exploring and practicing. Hampshire, Reino Unido: Palgrave Macmillan, 2011.

LOCK, G. Functional English Grammar: an introduction for second language teachers. Cambridge: Cambridge UniversityPress, 1996.

MACIEL, R. F. Negociando e reconstruindo conhecimentos e práticas locais: a formação de professores de língua inglesa e os documentos oficiais. 2013. 183 f. Tese (Doutorado em Estudos Linguísticos e Literários em Inglês) - Universidade de São Paulo. São Paulo. 2013.

MARTIN, J.; ROSE, D. Genre Relations: Mapping Culture. London: Equinox, 2008.

RAJAGOPALAN, K. The Role of Geopolitics in Language Planning and Language Politics in Brazil. Current Issues in Language Planning, v. 9, n. 2, 2008, p. 179192.

ROSE, D. Reading to learn: accelerating learning and closing the gap. Teacher resource books. Sydney: UTS, 2015.

ROSE, D.; MARTIN, J. R. Learning to write, Reading to learn: genre, knowledge and pedagogy in the Sydney School. Londres: Equinox, 2012.

ROTHERY, J.; STENGLIN, M. Entertaining and instructing: exploring experience through story. In: CHRISTIE, F.; MARTIN, J. Genre and Institutions. London and New York: Continuum, 2000. p. 231-265.

SANTOS, P. L. dos. As representações da língua inglesa no discurso de jovens carentes: um Estudo Crítico. 2011. 169 f. Dissertação (Mestrado em Linguística Aplicada) - Universidade Estadual de Campinas. Campinas. 2011.

SCHLEPPEGRELL, M. J. The Language of Schooling. A Functional Linguistics Perspective. Mahwah, NJ: Lawrence Erlbaum Associates, 2004.

SCHMIDT, A. P. C.; FIGHERA, A. C. M. O Ensino da Língua Inglesa na Educação de Jovens e Adultos e os Desafios para a Formação de Professores. Vivências (URI Erechim), v.12, n. 23, 2016, p.134 - 144.

ZACCHI, V. J. Discursos da globalização nas vozes de professores e professoras de língua inglesa. Trabalhos em Lingüística Aplicada, Campinas, v. 45, n.1, 2006, p. 9-27. 